\title{
Seven Methods in Creating Contemporary Paintings
} (Exploring Yeh Pulu Relief)

\author{
I Wayan Adnyana \\ Fine Art Study Program, Faculty of Visual Art and Desain, \\ Indonesia Institute of the Arts, Denpasar \\ kun_adnyana@yahoo.com
}

\begin{abstract}
This article aims to elaborate and explain the seven methods in creating contemporary paintings based on Yeh Pulu relief explorations. The methods used were carried out through the three stages of process based on the concept of Sullivan's 'Art Practice as Research' (2005): medium experimentation, visual language depiction and relevant context preparation. The seven methods in creating contemporary paintings were found as follows: (a) cutting (imagining that Yeh Pulu relief is like a comic poster sheet that can then be freely cut out); (b) coloring (giving colors according to the artist's artistic intention); (c) highlighting (making a certain subject/scene/plot of the relief the center of attention); (d) smashing (collating fragments and scraps of the relief that have become scattered due to rock corrosion); (e) drawing (construction of the visual subject based on a drawing/line technique); (f) layering (layers of transparent colors as the background) and (g) deconstructing (disposition and deconstruction of the scene/plot). Those seven methods are also referred to as the aesthetic approaches to painting that are used in the creation or as a combination of several approaches. Contemporary paintings which were then produced show that Yeh Pulu visual relief is presented in contemporary multi narration; a visual artifact interpreted visually into seven ways of expression.
\end{abstract}

Keywords: the seven aesthetic methods, contemporary painting, Yeh Pulu relief.

\section{INTRODUCTION}

The finding of the multi-narration concept in Yeh Pulu relief, based on the analysis of iconography (Adnyana, et. Al., 2018: 251), was used as a creative foundation for the creation of contemporary painting. The finding of this concept is an improvement in the meaning (interpretation of iconography / iconology) of the relief object located in Bedulu Village, Gianyar, Bali, namely that the one carved there is the everyday heroic theme of the ordinary/common people (Adnyana, 2017: 35). The finding of these concepts was obtained through act of interpretation, namely the pre-iconographic description stage, iconographic analysis, and iconographic interpretation (iconology) Panofsky, 1972: 14).

The concepts were then compared to Kempers' opinion, that the Yeh Pulu relief was seen as a single theme, namely the narrative of the heroism of Krishna (1978: 136-138). Kempers' view, as explained one of them through the 'bear hunt' scene, identified the relief as Krishna's fight against the Jambawat bear, whereas in the same scene, Kempers once called it a 'tiger hunt' scene (Kempers, 1959: 72). This inconsistency clearly emphasizes that there are so many gaps to carry out new analyzes and interpretations on Yeh Pulu reliefs, as the ones done through the three stages of the Iconological analysis.

As in the 'tiger hunt' scene through pre-iconographic descriptions, it is clear that the scene as 'bear hunt' has been refuted, that the character of a bear's face is longer than that of a tiger. Besides, seen from the character of the three hunters involved in the fight with the tiger, there is no single hunter who resembles the character of Krishna, who is usually armed with chakra. The three sculpted hunters are seen swinging badik (a traditional knive/short sword) (Adnyana, 2018: 154). Thus Kempers' view that stated the scene was Krishna fighting against Jambawat bear is actually very weak and not solid.

The findings of the multi-narration concept of everyday heroism of ordinary people in Bali, illustrated by Yeh Pulu relief, must be interpreted into the artistic method of contemporary painting. So that the concept can be absorbed as the 'spirit' which animates every work produced later. For this reason the theoretical basis associated with the practice of contemporary art is needed as a basis for creative experiments.

\section{LITERATURE REVIEW}

The references studied in the research related to the discovery of artistic methods of art creation, namely the Practice Practice as a Research book (Sullivan, 2005: 124-127), emphasize three stages of art creation, namely: exploration of the medium, discovery of visual language, and determination of relevant contexts. Each stage of the process will refer to the findings of artistic methods, 
which can then be interpreted into a process of creating contemporary painting.

The following reference is the iconological theory of Panofsky (1972: 14) outlining three stages of analysis: pre-iconographic descriptions, iconographic analysis, and iconographic interpretation (iconology). This theory has been used in the process of discovering work concepts, namely the multinational daily heroism of ordinary people as illustrated in the Yeh Pulu relief (Adnyana, et. $\mathrm{Al}, 2018:$ 251). This multinational concept is interpreted through the second stage of the research process, which is a studio experiment.

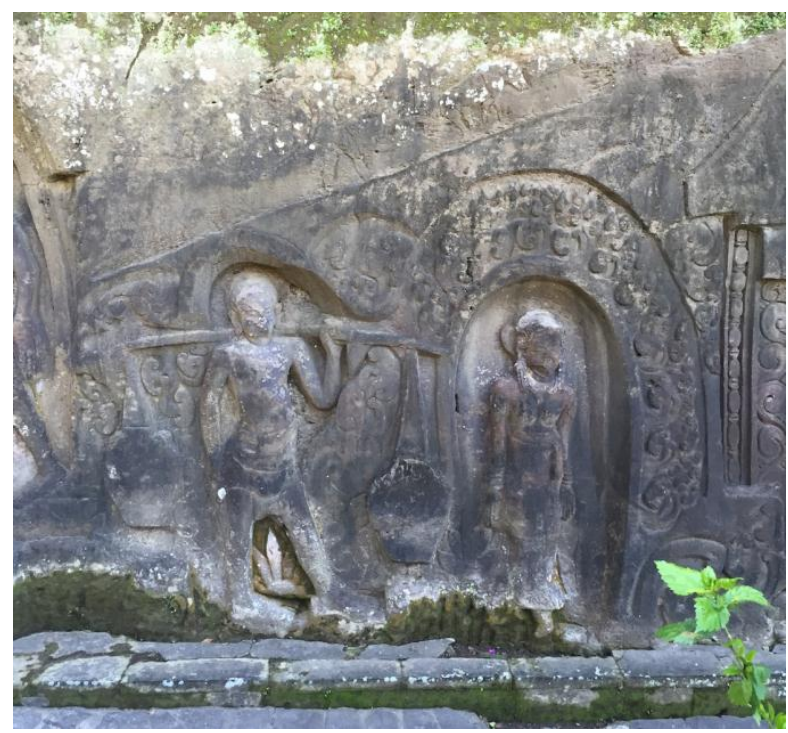

Figure 1, a scene of Balinese wine seller and a princess, Yeh Pulu reliefs, Bedulu, Gianyar, Bali. Photo by author.

Two books by Kempers: Monumental Bali (1978) and Ancient Indonesian Art (1959) were used as references related to the description and conceptual explanations that had been carried out by previous researchers on Yeh Pulu relief objects. The two books in question have inconsistent explanations in several parts, such as the naming and identification of scenes in Yeh Pulu relief, such as the mention of the 'tiger hunt' scene in a 1959 publication, turning into 'bear hunt' in a 1978 book. This inconsistency certainly provides an opportunity to carry out new analyzes and interpretations of the reliefs which was carved in the last era of ancient Balinese rule in Bali.

Finally, the findings of the multinational concept referred to the published research of the Mudra: Journal of Art and Culture, volume 33, Number 2, May 2018, with the article "Multi-naration of Yeh Pulu Relief Base on Contemporary Painting Creation" (Adnyana, et.al , 2018: 251). These articles describe the concept of 'multinarration' in framing the entire scene in reliefs with a length of 25 meters and an average height of 2 meters. The findings of the concept of 'multi-narration' is increasingly emphasizing that each scene can be selected as a subject matter of painting works, because basically every scene can stand alone, without having to be connected with other scenes.

\section{PROBLEM STATEMENTS}

This study aims to find the artistic method of contemporary painting, as the basis of creation based on the everyday concept of multi-narrative heroism of ordinary people from Yeh Pulu relief object. So the question that can be formulated is about how the discovery of artistic methods can be done, so that the created contemporary paintings can then interpret the intended multinational concept.

The process of discovering artistic methods was conducted through the stages of experimental research in the studio. This type of research is more directed at experiments with tools and materials, including techniques related to the process of creating contemporary painting.

\section{METHODOLOGY}

The research method for this creation was conducted by studio experiments. The experiments were based on three stages of creation theory in accordance with Art Practice as a Research (Sullivan, 2005: 124), namely: exploration of the medium, determination of visual language, and determination of relevant contexts. Each stage was carried out with relevant experimental patterns, namely (a) medium exploration was carried out in addition to testing materials and tools, also for discovering visual elements, such as lines and colors. And then on the stage of visual character determination, the analysis was directed to compositional findings such as theme, and other visual characteristics which conclude an authentic approach, so that a work created by a painter with other works by other painters can be distinguished, even when they take the same object like Yeh Pulu relief. The last stage was (c) determining the relevant context namely the efforts to find concepts that are more of aesthetic values.

Each stage pays attention to the concept of "ordinary people's multi-narrative heroism" as the result of an iconological analysis of the Yeh Pulu relief object. So that the methodology of syllogism between concepts as the basis of creation, and the artistic / aesthetic approach found in the process of creating contemporary paintings can be maintained.

\section{RESULTS OF ANALYSIS}

The studio experimental research has found seven artistic / aesthetic approaches, which include: (a) coloring (coloring method); (b) drawing (how to realize a drawing subject through line drawings); (c) smashing (how to break down the object image); (d) cutting (how to cut and randomly divide the drawing object); (e) highlighting (how to select the subject in focus so that it can be the 
center of attention on one canvas field; (f) layering (how to arrange color layers with imaginative spatial images, especially on the background of the painting); (g) deconstructing (disposition of the image subject, through reconstruction of the object image, like changing the prince on horseback into a princess on horseback, including by including popular culture icons in the work).

\section{DISCUSSION}

According to the art creation theory of Art Practice as a Research (Sullivan, 2005), there are three stages of process in creating contemporary art. The three stages in question are of course carried out through an experimental approach, namely contextual experiments with each stage of process. The entire trial processes were carried out in the studio.

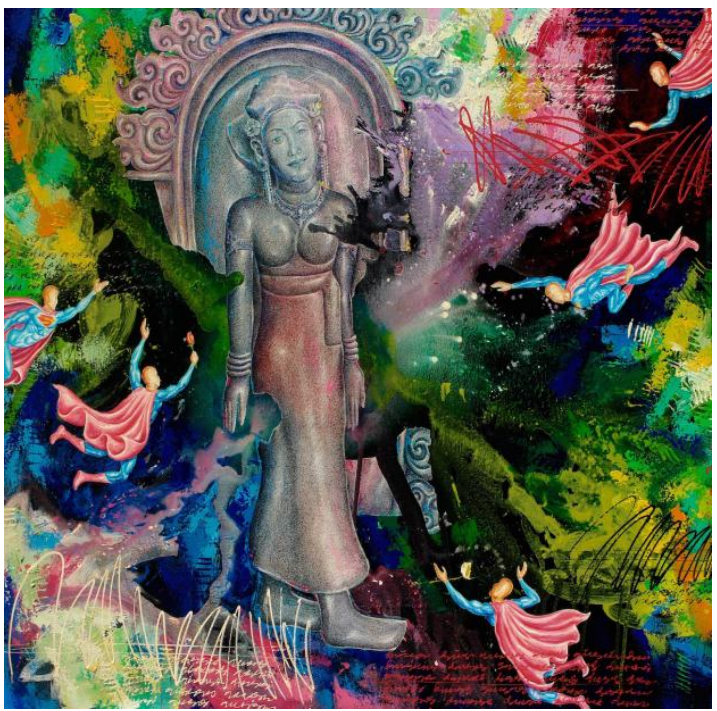

Figure 2, 'The Queen' contemporary art painting, $140 \times 160 \mathrm{Cm}, 2018$. photo by author.

In the first stage, the medium experiment, besides pointing to the finding of the materials and tools used in the creation of painting, the most important thing is the findings related to the technique. The techniques found in medium exploration namely the artistic approach in the forms of: (a) coloring (free coloring technique, mainly there are two main techniques, 'style' technique popular with various approaches to pop art, or vice versa, and the classical Balinese painting coloring which is known as sigar-mangsi technique). The Sigar Mangsi technique is a technique of coloring drawing objects with a monochrome color gradation pattern, from dark to light. The finding of the next approach was (b) drawing (line drawing techniques are the main technique in an effort to build the volume of a drawing subject). Line drawing techniques forms he volume or proportion of the drawing subject only with complex stacks of scratches and circular patterns. This is related to the use of medium Chinese ink on acrylic painting.

At the stage of visual language discovery, exploration was directed at the findings of the composition, theme, and character's characteristics of the drawing object. For the principle of composition, the approaches found were: (a) smashing (breaking down the image object, imagining reliefs in fragmented and scattered conditions). The 'breaking down' approach to the object of the drawing aims to test and invite concern for historical heritage objects, such as the existence of Yeh Pulu reliefs. Approach (b) was cutting (imagining Yeh Pulu reliefs like poster sheets, which are free to cut). The cutout results were used as a reference to be painted on the canvas so that the work appears with the impression of flat objects without volume, which complements the presence of volumes of images by a pile of line drawings. The next approach is (c) highlighting (selecting or choosing poses, scenes, or excerpts of Yeh Pulu relief objects, which was then used as a central point on one canvas field). The choice of a particular pose or scene was determined based on consideration, that the scene or pose is very prominent and is also very often referred to as the subject of a plot in relief.

While in the experimental stages of determining the relevant context, the analysis was more directed at finding aesthetic concepts, namely through: (a) deconstructing (disposition, or tracing of plots or scenes found in Yeh Pulu reliefs, with creative efforts to arrange scenes or certain plots). In this deconstruction approach two patterns were arranged, namely (1) through the disposition of plots, such as in the Yeh Pulu relief, there is a scene of a prince riding a horse, in a painting the prince is replaced with a princess riding a horse; (2) there was also an attempt to compare the hero figure in Yeh Pulu relief with the imaginary heroes of the animated world, such as Batman, Spiderman, or Shrek. Approaches to the relevant context also found the approach of: layering (layering of colors to build the impression of cosmic space, especially in the background of the work, transparent color layers form imaginative spatial impressions, so that all image subjects appear to float).

In the practice of creating contemporary painting works, the seven artistic approaches in question were not necessarily used all in one canvas field, but only the relevant approaches were chosen, depending on the consideration of which side will be highlighted in a given canvas field.

\section{CONCLUSION}

Based on the finding of the concept of "everyday multi-narrative heroism of the ordinary people " in Yeh Pulu relief iconology analysis, in the second stage, the experimental research in the studio had found seven artistic / aesthetic approaches. The seven approaches were obtained based on the experimental stages of the creation of contemporary art by Sullivan (2005) Art Practice as a Research, which relies on three stages of creation, namely: exploration of the medium, formulation 
of visual language, and determination of relevant contexts.

The seven artistic / aesthetic approaches found include: coloring and drawing (for visual elements / elements obtained from medium exploration), highlighting, cutting, and smashing (for visual language elements in the form of compositions, themes, and characteristics of drawing subject). And the layering and deconstructing are the elements of themes and aesthetic concepts.

These seven artistic / aesthetic approaches can be used as a reference in the creation of contemporary painting with character. The seven approaches were found after the findings of the 'multi-narration' concept which made the iconographic research on Yeh Pulu relief as the basis for the creation of authentic contemporary painting.

This research was fully funded by the 2018 applied research scheme, Directorate of Research and Community Service, Ministry of Research, Technology and Higher Education, Republic of Indonesia, in Jakarta.

\section{REFERENCES}

University Press, Cambridge, Massachusetts.
Adnyana, I Wayan. 2017, Ikonografi Kepahlawanan Relief Relief Yeh Pulu (Penelitian, Penciptaan, dan Penyajian Seni) (sebuah buku ajar), Arti, Denpasar.

2018, "Tiger-Hunting Scene on Yeh Pulu Relief in Bali. Romanticism of People's Heroism in Study of Iconology" published in Cultura International Journal of Philosophy of Culture and Axiology (15/1), 2018: 147-160.

Adnyana, I Wayan, et.al,. 2018, "Multinarasi Relief Yeh Pulu, Basis Penciptaan Seni Lukis Kontemporer", dalam Mudra: Jurnal Seni Budaya, Volume 33, No 2, Mei 2018: 89-95, Pusat Penerbitan ISI Denpasar, Denpasar

Kempers, A.J. Bernet. 1959, Ancient Indonesia Art, Harvard

1978, Monumental Bali, Van Goor Zonen, Den Haag.

Panofsky, Erwin. 1972, Studies in Iconology, Icon Edition, Colorado.

Sullivan, Graeme. 2005, Art Practice as Research, Sage Publication, London 